\title{
Clinical Observations Severity
}

National Cancer Institute

\section{Source}

National Cancer Institute. Clinical Observations Severity. NCI Thesaurus. Code C119810.

The degree of something undesirable as determined by clinical observations. 